\title{
MYOCARDIAL FIBROSIS IN FIBROCYSTIC DISEASE OF THE PANCREAS
}

\author{
BY \\ A. R. MCGIVEN \\ From the Department of Pathology, University of Otago Medical School, New Zealand
}

(RECEIVED FOR PUBLICATION JULY 9, 1962)

The association of myocardial fibrosis with fibrocystic disease of the pancreas has only occasionally been observed. It is not mentioned by Farber (1944) in his review of 87 cases of pancreatic fibrocystic disease at autopsy or by Bodian (1952) in his monograph. One American, four French and three German cases have previously been reported.

\section{Case Report}

The patient was a girl aged 2 years and 8 months who was known to suffer from pancreatic fibrocystic disease. She was subject to persistent bronchitis with frequent exacerbations that necessitated several courses of antibiotics, including chloramphenicol, erythromycin and novobiocin. She was also treated with vitamin A and vitamin D.

On admission to hospital on March 23, 1961, she had a temperature of $100^{\circ} \mathrm{F}$. $\left(37 \cdot 8^{\circ} \mathrm{C}\right.$.), was cyanosed with an irregular pulse of 120 per minute, raised jugular venous pressure and a palpable liver. Chest radiograph showed generalized cardiac enlargement with hilar congestion (Fig. 1). An electrocardiogram (Fig. 2) showed atrial fibrillation and a right bundle-branch block. Nonprotein nitrogen was $42 \mathrm{mg}$. $/ 100 \mathrm{ml}$. Serum electrolyte levels were sodium $139 \mathrm{mEq} / \mathrm{l}$., potassium $5.3 \mathrm{mEq} / \mathrm{l}$., chloride $101 \mathrm{mEq} / \mathrm{l}$, and $\mathrm{CO}_{2}$-combining power $19.8 \mathrm{mEq} / \mathrm{l}$. Treatment with intramuscular digoxin was commenced, but the patient died the day after admission.

Autopsy. The body was that of a thin pale girl weighing $11.5 \mathrm{~kg}$. No abnormality was found in the genito-urinary, central nervous, skeletal, haemopoietic and lymphoreticular systems.

The pancreas felt firm and had a slender elongated appearance due to reduction in its supero-inferior diameter. No macroscopic cystic changes were present.

The liver weighed $410 \mathrm{~g}$. and was congested.

The main bronchi were filled with mucopurulent sputum, and the lungs showed confluent patches of bronchopneumonia.

The heart (Fig. 3) showed dilatation and hypertrophy of both ventricles and weighed $105 \mathrm{~g}$. The chamber of the left ventricle measured $5.0 \times 3.5 \times 2.5 \mathrm{~cm}$. and its wall measured $1.0 \mathrm{~cm}$. in thickness at its base. The chamber of the right ventricle measured $4.5 \times 4.0 \times 2.5 \mathrm{~cm}$. and its wall $0.4 \mathrm{~cm}$. in thickness at the base. The epicardium contained very little fat, and there were a number of small petechial haemorrhages on the posterior and lateral aspects of the left ventricle. The left atrium, including its appendage, showed a uniform fibrous thickening of the whole endocardium which measured $2 \mathrm{~mm}$. in thickness. The right atrium showed slight fibrous thickening of the endocardium, which did not involve the musculi pectinati. The thickened wall of the left ventricle macroscopically presented widespread irregular fibrosis with several areas of coarse scarring which also involved the septum.

\section{Histology}

Pancreas. There was extensive fibrosis with loss of acini and gross dilatation of ducts which contained eosinophilic inspissated secretion.

Liver. Widespread fatty change involved the centrilobular and mid-zonal regions.

Heart. Beneath the endothelium of the left atrium was a thick layer of densely packed elastic fibres which gradually gave way to an increasing number of collagen fibres adjacent to the myocardium. The wall of the left ventricle showed patchy replacement of muscle fibres by fibrous connective tissue involving the myocardium mainly towards its epicardial aspect. In some areas dense collagen enclosed endothelium-lined vascular spaces. In other areas muscle fibres had been lost, but only a few fine collagen fibres had been laid down. Some of the adjacent degenerating muscle fibres showed bizarre nuclear forms. No inflammatory cells were present. (See Figs. 4-7.)

\section{Discussion}

There are already eight reported cases of myocardial fibrosis occurring in association with fibrocystic disease of the pancreas. In 1945 Wissler and Zollinger (quoted by Powell, Newman and Hooker, 1957) reported this association in a child of 8 months. Subsequently Kintzen (1950) and Feer (1952) reported two cases occurring in children aged 18 months and 7 months respectively. Powell et al. (1957) reported the case of a boy aged 2 years 7 months, and Nezelof and Lancret (1959) found four cases aged 18 months, 8 months (two cases) and 1 day respectively in a series of 44 cases of fibrocystic 


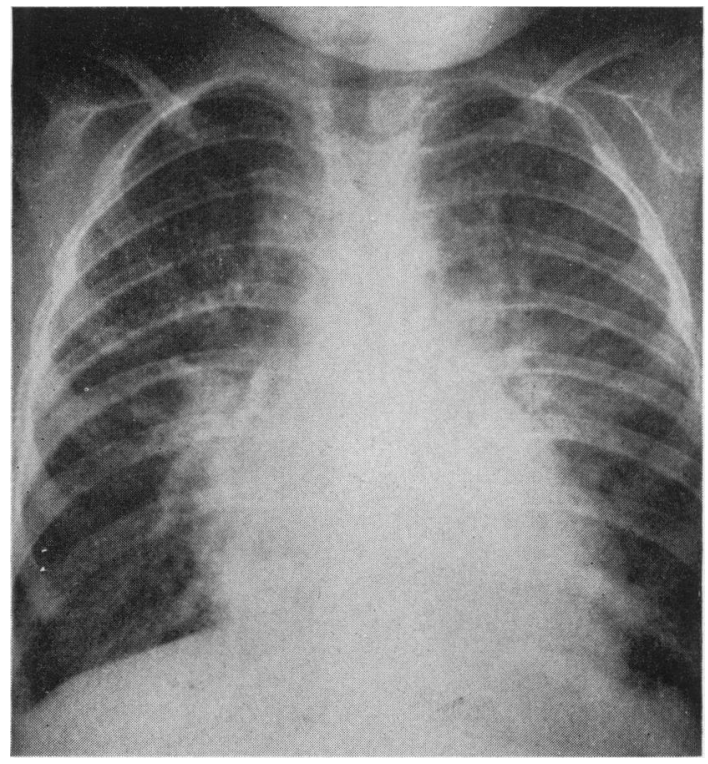

FIG. 1.-Radiograph showing cardiac enlargement and hilar congestion.

disease of the pancreas, which they reviewed. In addition, Eastager presented a thesis in Paris on this subject in 1958 (Nezelof and Lancret, 1959). Most of the reported cases were characteristic of pancreatic fibrocystic disease, and after showing a variable response to treatment with antibiotics and pancreatic extracts they went into congestive heart failure and succumbed rapidly. An exception was the 1-day-old infant who presented with a meconium ileus and died during laparotomy. Feer's case, in addition, suffered from xerophthalmia which responded to vitamin A. Autopsies revealed the typical findings of pancreatic fibrocystic disease usually in association with an extensive bronchopneumonia complicating a purulent bronchitis. In the heart, dilatation was usually more prominent than hypertrophy and the left ventricle was more affected than the right. In the myocardium degenerating muscle fibres were replaced by dense scar tissue. In the case reported by Kintzen (1950) there was vacuolation of the degenerating muscle fibres and much interstitial oedema. Feer (1952), Powell et al. (1957) and Nezelof and Lancret (1959) reported patchy areas of fibrosis which often became confluent. Adjacent to these areas of fibrosis, degenerating muscle fibres showed atrophy and fragmentation with nuclear pyknosis and loss of striations. The extent of the fibrosis was variable and took the form of scattered stellate areas or of an almost continuous fibrous ring. Usually the

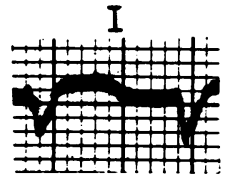

aVR

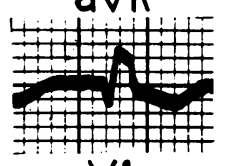

V1
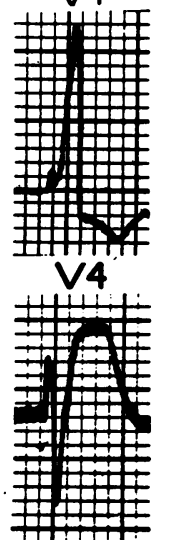

Fig. 2.-Electrocardiogram showing atrial fibrillation and a right bundle-branch block.

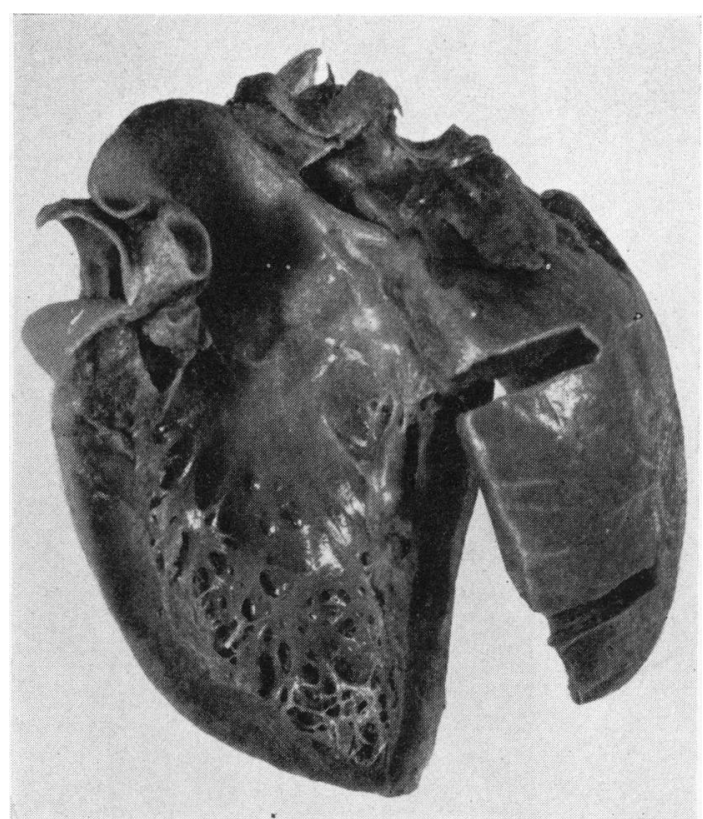

Fig. 3.-Heart showing hypertrophy of the left ventricle with pale areas of myocardial fibrosis.

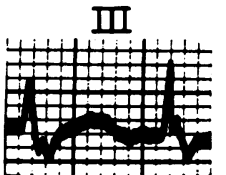

ovF

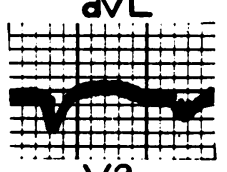
V2

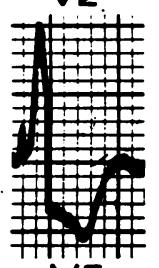

V5
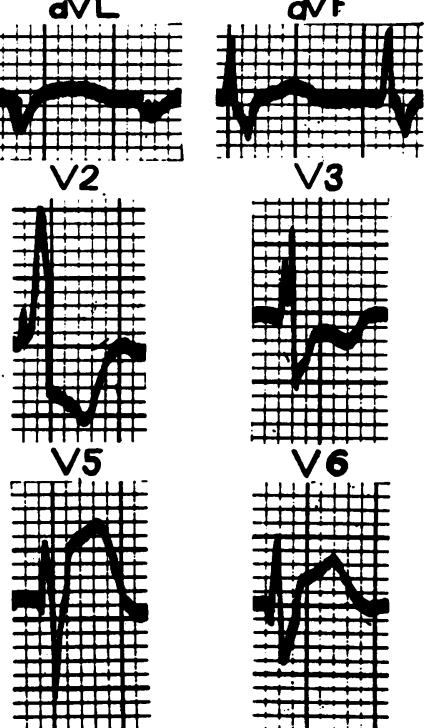

V3
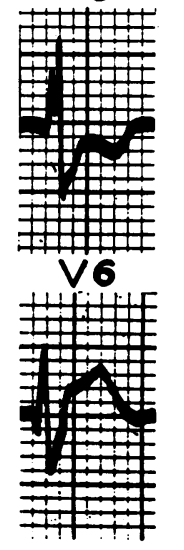

으.

吾

T

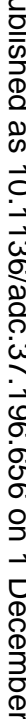

$8 \overrightarrow{0}$

유

\section{ก}




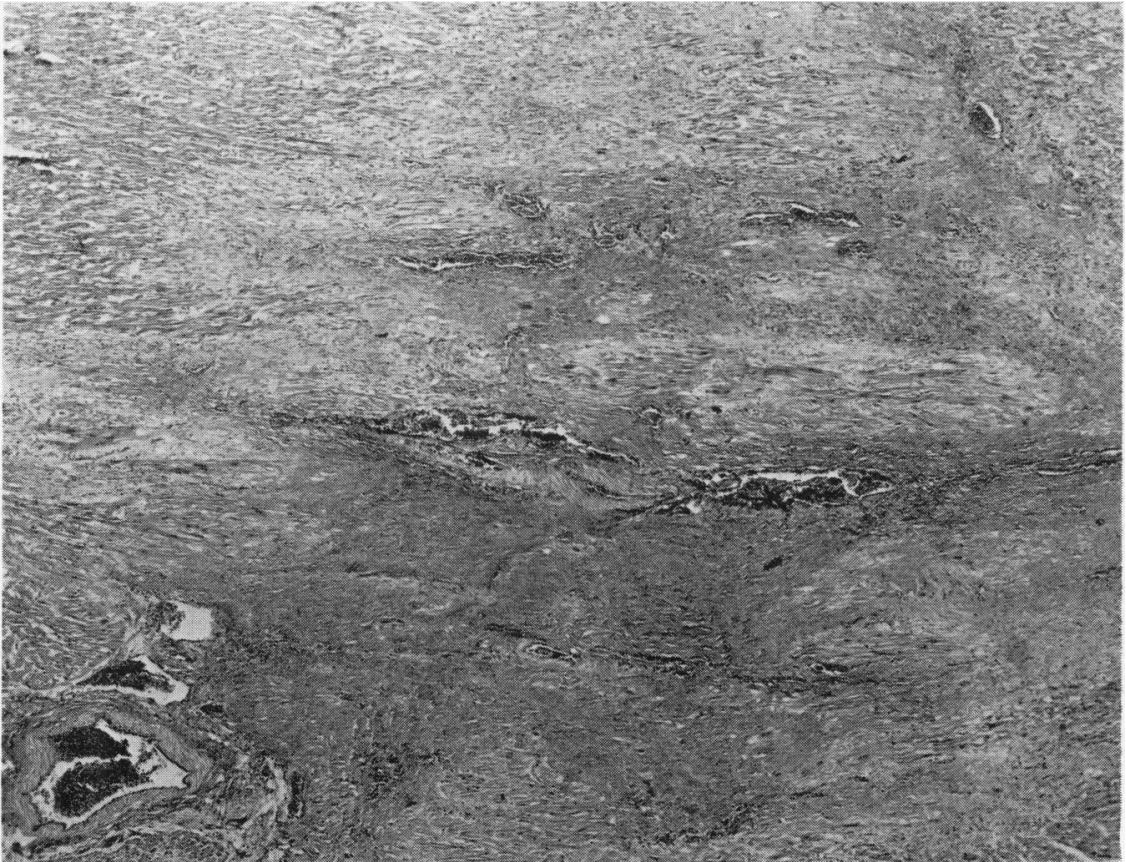

Fig. 4.-Irregular vascular areas of fibrosis in the myocardium of the left ventricle. (Van Gieson elastic $\times 30$.)

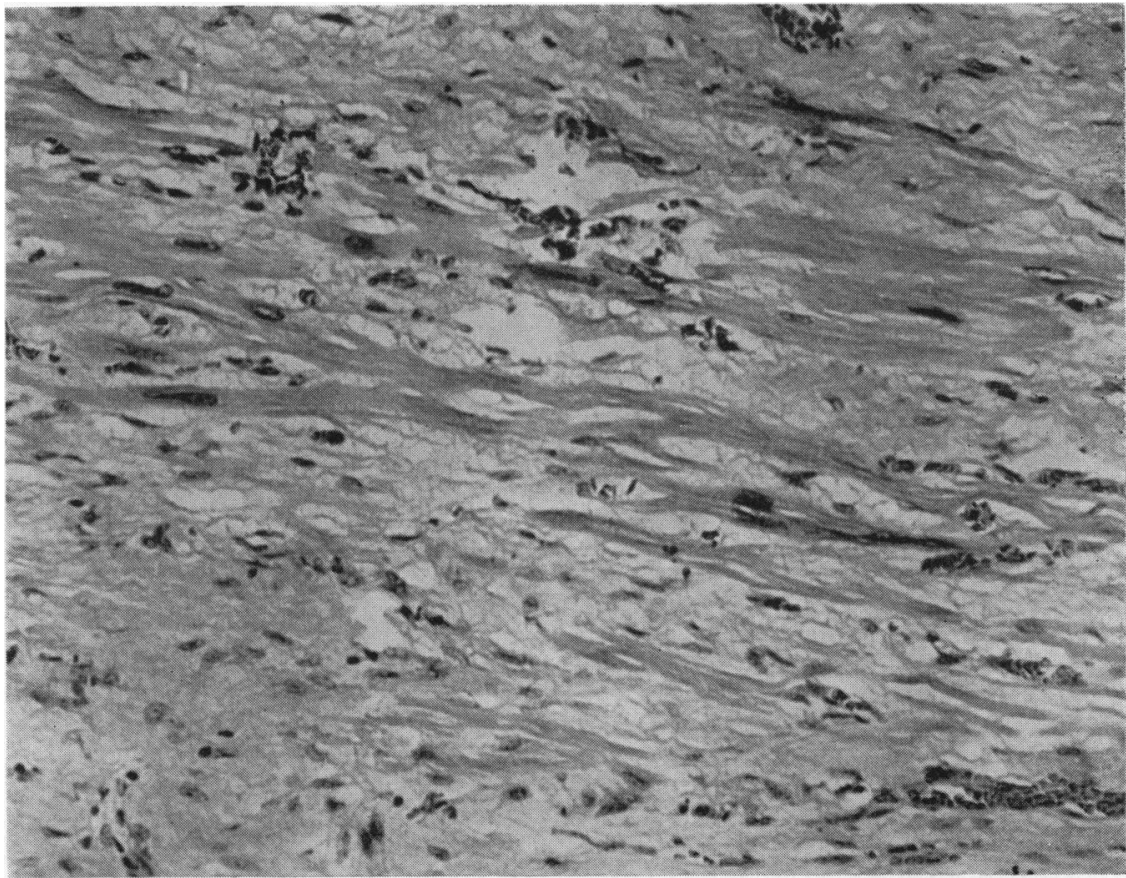

Fig. 5.-Left ventricle showing loss of muscle fibres and replacement by loose vascular connective tissue. (Haematoxylin and eosin $\times$ 200.) 
fibrous areas lay in the middle of the myocardium and sent expansions towards the endocardium and epicardium. Histologically these lesions presented numbers of fine collagen fibres together with fibroblasts, histiocytes, capillaries and small arterioles. No marked inflammatory reaction has been reported and usually inflammatory cells are not prominent. Bacteria, fungi and abnormal pigments have not been found in relation to these areas of myocardial degeneration.

The case reported here presents the previously noted dilatation and hypertrophy of the heart, together with patchy fibrosis of the left ventricle. In addition there is endocardial fibroelastosis of the left atrium to some extent resembling the case of the 18-month-old child reported by Nezelof and Lancret (1959), which showed endocardial thickening as well as extensive myocardial fibrosis. The vascularity of the myocardial lesions and the absence of an active inflammatory response is a striking feature.

The aetiology of the cardiac lesion is uncertain and metabolic or nutritional disorders seem to be the most likely factors involved. Several types of nutritional deficiency are recognized as causing myocardial necrosis and scarring. In the experimental animal deficiencies of potassium, aneurine

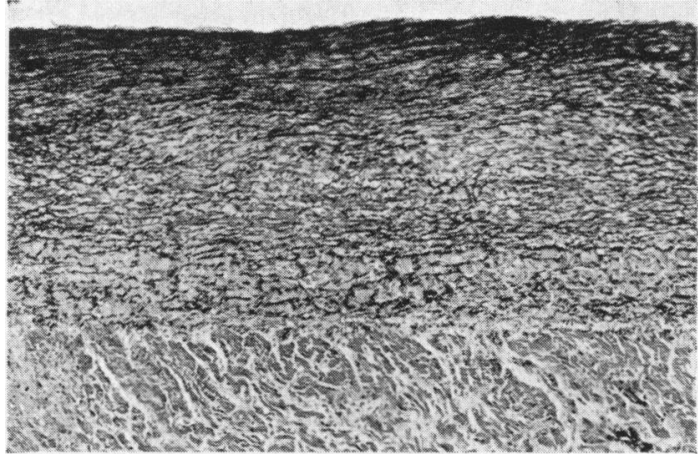

Fig. 6.-Fibroelastosis of the left atrium. (Van Gieson elastic $\times 51$.)

and tocopherol have all produced myocardial degeneration with fibrosis. In potassium-deficient rats Macpherson (1956) produced lesions characterized by the absence of a polymorphonuclear leucocyte response.

Aneurine deficiency in many animals, including dogs, pigs, rats and monkeys, has led to myocardial necrosis and fibrosis. Swank, Porter and Yeomans (1941) working with dogs found dilatation of the left ventricle and scattered areas of myocardial

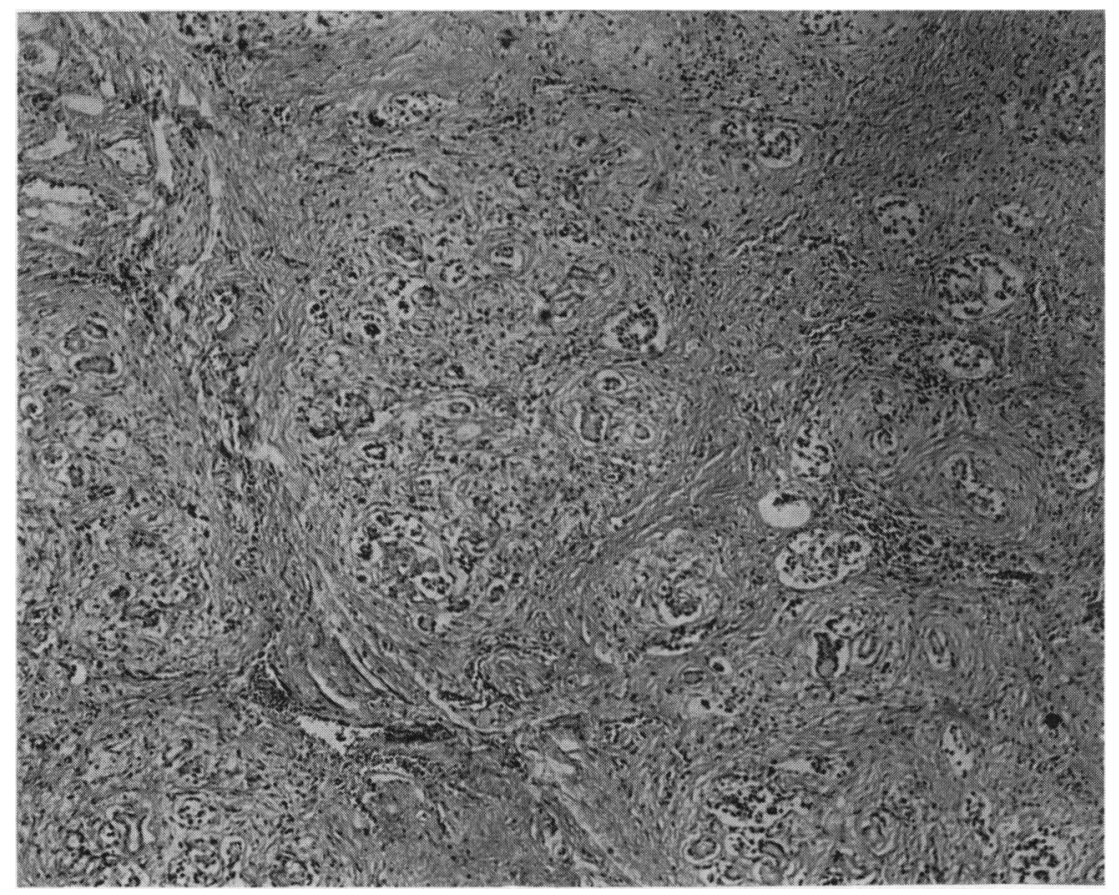

FIG. 7.-Fibrosis of the pancreas with loss of acini.

(Haematoxylin and eosin $\times 65$.) 
necrosis. Follis, Miller, Wintrobe and Stein (1943) reported widespread areas of necrosis in the atria and ventricles in six out of nine aneurine-deficient pigs. In rats Ashburn and Lowry (1944) demonstrated lesions mainly confined to the atria. Finally, in the rhesus monkey, Rinehart and Greenberg (1949) found cardiac dilatation particularly in the right ventricle and microscopic focal areas of necrosis or 'hydropic' swelling of the subendocardial fibres of the conducting system.

Tocopherol deficiency in rabbits has been shown by Bragdon and Levine (1949) to produce necrotic and even calcified myocardial lesions particularly in the papillary muscles and posterior walls of the ventricles.

Clinically, similar deficiencies have been credited with producing myocardial lesions. Rodriguez, Wolfe and Bergstrom (1950) have reported two cases of diabetic acidosis, one a boy aged 2 years, the other a woman aged 77 years, in which foci of myocardial necrosis associated with oedema, fragmentation of muscle fibres and lymphocytic infiltration were attributed to potassium deficiency. In beri-beri Weiss and Wilkins (1937) have described cardiac dilatation, particularly of the right ventricle with 'hydropic' degeneration of myocardial and conducting fibres. Oppenheimer (1956) found focal necrotic lesions which were attributed to tocopherol deficiency in the skeletal muscles of a child with fibrocystic disease of the pancreas, but there were no such lesions in the heart.

It is possible that deficiencies of potassium, aneurine and tocopherol may be present together or separately in children suffering from fibrocystic disease of the pancreas. In the case studied the serum potassium was normal and no ceroid pigment was found in the smooth muscle of sections taken from the alimentary tract. Blanc, Reid and Andersen (1958) found this pigment in the smooth muscle layers of the gastro-intestinal tract in 37 out of 38 children over the age of 2 years with fibrocystic disease of the pancreas and took this to be evidence of tocopherol deficiency. However, deficiency of aneurine is not unlikely and the clinical picture of sudden cardiac failure followed by a rapid downhill course is consistent with that reported in infantile beri-beri. Histologically there is no pathognomonic cardiac lesion in beri-beri, yet the foci of myocardial degeneration, with replacement by proliferating fibroblasts laying down collagen, resemble the lesions found in experimental aneurine deficiency. Nezelof and Lancret (1959) suggest that such a deficiency may be related to steatorrhoea and prolonged antibiotic therapy with alterations in the intestinal flora.

At present the cause of myocardial fibrosis in fibrocystic disease of the pancreas remains obscure. As Powell et al. (1957) point out, cor pulmonale is not the only cause of heart failure in children with fibrocystic disease of the pancreas.

\section{Summary}

A girl aged 2 years and 8 months with fibrocystic disease of the pancreas was admitted to hospital in congestive heart failure. At autopsy the heart was dilated and both ventricles were hypertrophied. The myocardium of the left ventricle showed extensive fibrosis with coarse scarring and the left atrium showed fibroelastic thickening of the endocardium. Although the aetiology of the cardiac lesion remains uncertain, the influence of possible nutritional deficiencies is discussed.

I am indebted to Dr. J. M. Lord for permission to publish clinical details of her case, to Dr. R. A. Rodda and Dr. T. P. Casey for their helpful criticism, and to Mr. G. A. Brook and Mr. D. V. Weston of the Photographic Unit.

\section{REFERENCES}

Ashburn, L. L. and Lowry, J. V. (1944). Development of cardiac lesions in thiamine-deficient rats. Arch. Path., 37, 27.

Blanc, W. A., Reid, J. D. and Andersen, D. H. (1958). Avitaminosis $E$ in cystic fibrosis of the pancreas. A morphologic study of gastrointestinal and striated muscle. Pediatrics, 22, 494.

Bodian, M. (1952). Fibrocystic Disease of the Pancreas. Heinemann, London.

Bragdon, J. H. and Levine, H. D. (1949). Myocarditis in vitamin Edeficient rabbits. Amer. J. Path., 25, 265.

Farber, S. (1944). Pancreatic function and disease in early life. V. Pathologic changes associated with pancreatic insufficiency in early life. Arch. Path., 37, 238.

Feer, W. (1952). Xerophthalmie und Myokardschaden bei Pancreasfibrose. Schweiz. med. Wichr., 82, 102

Follis, R. H., Miller, M. H., Wintrobe, M. M. and Stein, H. J. (1943) Development of myocardial necrosis and absence of nerve degeneration in thiamine deficiency in pigs. Amer. J. Path., degeneratio
1941 .

Kintzen, W. (1950). Zystische Pankreasfibrose kombiniert mit Myokardfibrose. Int. Z. Vitamin-forsch., 22, 273.

Macpherson, C. R. (1956). Myocardial necrosis in the potassiumdepleted rat: A reassessment. Brit. J. exp. Path., 37, 279.

Nezelof, C. and Lancret, P. (1959). Lésions de fibrose myocardique au cours de la maladie fibro-kystique du pancréas. Arch. franc. Pédiat 16, 1035 .

Oppenheimer, E. H. (1956). Focal necrosis of striated muscle in an infant with cystic fibrosis of the pancreas and evidence of lack of absorption of fat-soluble vitamins. Bull. Johns Hopk. Hosp., $98,353$.

Powell, L. W., Newman, S. and Hooker, J. W. (1957). Cystic fibrosis of the pancreas complicated by myocardial fibrosis. Virginia med. Mth., 84, 178.

Rinehart, J. F and Greenberg L. D. (1949). Effect of experimental thiamine deficiency on the heart of the rhesus monkey. Arch. Path., 48, 89 .

Rodriguez, C. E., Wolfe, A. L. and Bergstrom, V. W. (1950). Hypokalemic myocarditis. Amer. J. clin. Path., 20, 1050.

Swank, R. L., Porter, R. R. and Yeomans, A. (1941). The production and study of cardiac failure in thiamin-deficient dogs. Amer. Heart J., 22, 154 .

Weiss, S. and Wilkins, R. W. (1937). The nature of the cardiovascular disturbances in nutritional deficiency states (beriberi) Ann. intern. Med., $11,104$. 